\title{
Relações entre caracteres de tubérculo de batata nas primeiras gerações de seleção
}

\author{
Giovani Olegario da Silva ${ }^{1}$, Vicenti Gonçalves Ney², Arione da Silva Pereira ${ }^{3}$, Laerte Reis Terres ${ }^{4}$
}

\begin{abstract}
RESUMO
O objetivo deste trabalho foi verificar a relação entre caracteres fenotípicos de tubérculo avaliados em progênies de batatas, nas gerações de plântula e primeira geração clonal. Os experimentos foram realizados na Embrapa Clima Temperado, em Pelotas, RS. Foram avaliadas, nas gerações de plântula, 12 progênies de batatas, cultivadas em casa de vegetação na safra de 2010/2011, e primeira geração de campo, cultivadas na safra de 2011/2012. O delineamento, em ambos os experimentos, foi o de blocos ao acaso, com três repetições de 25 plântulas para cada progênie. Após as colheitas, os tubérculos de cada planta foram avaliados para 14 caracteres fenotípicos. Foram realizadas análises de variância individuais e conjunta para as gerações e, análises de correlação entre as gerações, e de trilha, dentro das gerações. Os caracteres aparência e aspereza de tubérculo; curvatura e apontamento; massa e número de tubérculos, proeminência da sobrancelha e profundidade de olhos são fortemente e favoravelmente correlacionados nas duas primeiras gerações de seleção. O grau de correlação entre as duas primeiras gerações para profundidade de olho, proeminência de sobrancelha, massa de tubérculo, número de tubérculos, curvatura de tubérculo e apontamento de tubérculo indica que a seleção para estes caracteres pode ser aplicada na geração de plântula. Aspereza e curvatura de tubérculo são os caracteres que mais influenciam na aparência geral; portanto, sua seleção pode ser utilizada no melhoramento para aparência geral de tubérculo.
\end{abstract}

Palavras-chave: Solanunm tuberosum L., correlações, análise de trilha, efeitos direto e indireto.

\section{ABSTRACT}

\section{Relationships among potato tuber traits in early generations of selection}

The objective of this study was to evaluate the relationships among tuber traits in potato progenies in the seedling generation and in the first clonal generation. The experiments were carried out at Embrapa Clima Temperado, in Pelotas, RS. Twelve potato progenies were grown as seedling generation in a greenhouse in the crop year 2010/2011 and the first field generation was grown in the crop year 2011/2012. The two trials were arranged in a randomized complete block design with tree replications of 25 seedlings per family. After harvest, tubers of each plant were evaluated for 14 phenotypic traits. Individual and joint analyses of variance were performed for the generations As well as correlation analysis between generations and path analysis for each generation. The correlations between tuber appearance and skin roughness; tuber curvature and pointing; weight and number of tubers; and eyebrow prominence and eye depth are strongly and positively correlated in the first two generations of selection. The correlation between the first two generations for eye depth, eyebrow prominence, tuber weight, tuber number, tuber curvature and tuber pointing indicates that selection for these traits can be applied in the seedling generation. Roughness and tuber curvature are the characteristics that most influence the overall appearance, thus the selection of these characters can be used to improve the tuber overall appearance.

Key words: Solanum tuberosum L., correlations, path analysis, direct and indirect effects.

Recebido para publicação em 17/05/2013 e aprovado em 26/08/2013.

${ }^{1}$ Engenheiro- Agrônomo, Doutor. Embrapa Hortaliças/SPM, Rodovia BR 280, Km 231, n 1151, Caixa Postal 317, 89460-000, Canoinhas, Santa Catarina, Brasil. giovani.olegario@embrapa.br (autor correspondente).

${ }^{2}$ Engenheiro- Agrônomo, Mestre. Embrapa Clima Temperado, Rodovia BR 392, Km 78, Caixa Postal 403, 96001-970, Pelotas, Rio Grande do Sul, Brasil. vicentig@gmail.com ${ }^{3}$ Engenheiro -Agrônomo, Doutor. Embrapa Clima Temperado, Rodovia BR 392, Km 78, Caixa Postal 403, 96001-970, Pelotas, Rio Grande do Sul, Brasil. arione.pereira@embrapa.br ${ }^{4}$ Engenheiro -Agrônomo, Mestre. Embrapa Clima Temperado, Rodovia BR 392, Km 78, Caixa Postal 403, 96001-970, Pelotas, Rio Grande do Sul, Brasil. laerte_terres@ yahoo.com.br 


\section{INTRODUÇÃO}

No Brasil, a batata figura entre os dez principais produtos agrícolas. No entanto, o país produz apenas $1 \%$ do total mundial, o que corresponde a cerca de 3,4 milhões de toneladas, em aproximadamente 144 mil hectares. $\mathrm{O}$ maior estado produtor de batata no Brasil é Minas Gerais, com aproximadamente $33 \%$ da oferta anual, seguido por Paraná (21\%) e São Paulo (17\%). O Rio Grande do Sul situa-se em quarto lugar (10\%). Estes quatro estados totalizam mais de $80 \%$ da produção brasileira (Agrianual, 2012).

Embora a produtividade tenha aumentado em média mais que $2,7 \%$, nos últimos anos, justifica-se a necessidade de buscar materiais mais produtivos, adaptados e resistentes, com o objetivo de reduzir custos de produção, que se mantêm elevados por causa, principalmente, do uso de cultivares pouco adaptados às condições subtropicais e tropicais brasileiras (Camargo Filho, 2001).

Várias são as características que devem ser consideradas pelo melhorista de batata no momento da seleção. Dentre elas, muita importância é dada ao rendimento de tubérculos, objetivando maior rentabilidade para os produtores, e à aparência dos tubérculos, possibilitando sua aceitação in natura, pelo mercado. O desafio de atender a essas exigências requer boa eficiência dos programas de melhoramento em identificar genótipos superiores. Portanto, procedimentos que venham oferecer informações para auxiliar na escolha da melhor estratégia de seleção são ferramentas importantes. Como exemplo, pode-se citar o uso de análises de correlação entre caracteres para o melhor entendimento das relações genéticas entre eles (Silva et al., 2009).

Caracteres mais complexos, como a aparência dos tubérculos, são governados por vários genes sujeitos a grande influência ambiental. Características quantitativas como estas podem ser selecionadas por via de seleção indireta de caracteres mais simples, que sejam a elas correlacionados, podendo, portanto, ser melhorados mesmo que não ocorra seleção direta (Cruz \& Regazzi, 2001).

A utilização da análise de trilha permite desdobrar coeficientes de correlação simples em seus efeitos diretos e indiretos, possibilitando o entendimento das relações de causa e efeito entre as variáveis estudadas (Barbosa, 1996; Carvalho et al., 2004).

Normalmente, nos programas de melhoramento de batata, inicia-se o processo de seleção nas gerações de campo (gerações clonais), sendo que a pressão de seleção nas primeiras gerações varia de um programa para outro e, muitas vezes, não é alta. No entanto, a eliminação dos genótipos inferiores o mais cedo possível, por menor que seja a pressão de seleção, implica redução de gastos com mão de obra, materiais de consumo e área de plantio nas sucessivas gerações de cultivo, possibilitando direcionar esforços para populações que proporcionem maior probabilidade de obtenção de genótipos superiores. Para iniciar a seleção nas gerações iniciais, como na geração de plântula, é necessário que as características já estejam expressas nesta fase, que é caracterizada por tubérculos pequenos e em número reduzido. Isso pode ser calculado com a determinação da herdabilidade, que é um indicativo da superioridade fenotípica de origem genética, que pode ser transmitida aos descendentes; neste caso, a herdabilidade pode ser medida com a correlação dos caracteres entre as gerações (Silva et al., 2011).

O objetivo deste trabalho foi verificar a relação entre caracteres fenotípicos de tubérculos, avaliados em progênies de batatas, na geração de plântula e na primeira geração clonal.

\section{MATERIAL E MÉTODOS}

Os experimentos foram realizados em Pelotas, $\mathrm{RS}\left(31^{\circ}\right.$ $\mathrm{S}, 52^{\circ} \mathrm{W}, 50 \mathrm{~m}$ a.n.m.). Foram avaliadas 12 progênies de batata originadas de cruzamentos controlados entre sete genitores, escolhidos ao acaso, para representar o bloco de cruzamentos, em esquema de dialelo parcial de dois grupos de genitores $(3 \mathrm{x} 4)$. O primeiro grupo foi formado pelos genitores BRS Eliza, C1730-7-94 e C1742-895 e, o segundo, por: Shepody, Asterix, White Lady e Caesar.

Na safra de 2010/2011, foi produzida a geração de plântulas, em casa de vegetação. As sementes botânicas foram germinadas em sementeiras e as plântulas transplantadas para sacos plásticos, contendo dois litros de substrato comercial, para produção de minitubérculos. As plântulas foram distribuídas em blocos ao acaso, com três repetições. Cada parcela foi composta de uma amostra de 25 plântulas, escolhidas aleatoriamente para representar cada cruzamento. As plântulas foram mantidas nessas condições desde o plantio, realizado em 20 de agosto de 2010, até a colheita, que ocorreu aos 77 dias após a germinação, quando os tubérculos foram transportados para instalações apropriadas para serem efetuadas as avaliações. Após as avaliações, os tubérculos foram armazenados em câmara fria a $4{ }^{\circ} \mathrm{C}$.

Na safra 2011/2012, foi produzida a primeira geração clonal. Um tubérculo de cada genótipo foi plantado a campo, utilizando-se o mesmo delineamento experimental da safra anterior. Após a maturação, que ocorreu aos 95 dias após o plantio, que foi realizado no dia 17 de agosto de 2011, as plantas foram colhidas separadamente e realizadas as avaliações nos tubérculos. 
Os caracteres avaliados em ambas as gerações foram: número de tubérculos por planta, massa total de tubérculos por planta $\left(\mathrm{g} \mathrm{planta}^{-1}\right)$, massa média de tubérculos $(\mathrm{g})$, aspereza de tubérculo (1- áspero, 9- liso), profundidade de olhos (1- profundo, 9- superficial), proeminência de sobrancelha (1- proeminente, 9- superficial), formato de tubérculo (1- redondo, 9- alongado), uniformidade de formato de tubérculo (1- desuniforme, 9- uniforme), apontamento de tubérculo (1- apontado, 9- não apontado), curvatura de tubérculo (1- curvado, 9- não curvado), achatamento de tubérculo (1- achatado, 9- não achatado), tamanho de tubérculo (1- pequeno, 9- grande), uniformidade de tamanho de tubérculo (1- desuniforme, 9- uniforme) e aparência geral de tubérculo (1- aparência geral ruim, 9boa aparência geral). Foram considerados de boa aparência aqueles tubérculos que apresentaram, conjuntamente, pele lisa, olhos pouco profundos, sobrancelha superficial, boa uniformidade de formato, não apontados, não curvados, não achatados e com boa uniformidade de tamanho.

Foi aplicado o teste de Lillifors (Campos, 1983) para averiguar se os resíduos estão normalmente distribuídos, e o teste de Bartlett, para verificar a ocorrência de homogeneidade de variância (Steel \& Torrie, 1980). Foram realizadas análises de variância para cada geração e análise conjunta das duas gerações. Os efeitos das fontes de variação de gerações e de genótipos foram considerados fixos.

Buscando determinar o grau de associação entre os caracteres, foi realizada a análise de correlação de Spearman, em ambas as gerações, para todos os caracteres, seguindo-se o modelo estatístico descrito por Siegel (1975). A matriz de correlação foi verificada quanto à multicolinearidade e foi realizada a análise de trilha, de modo a identificar a magnitude dos efeitos diretos e indiretos dos caracteres influenciando na aparência de tubérculo.

Foi realizada, também, análise de correlação fenotípica entre as gerações, visando a identificar a repetibilidade da expressão dos caracteres nas diferentes gerações.

As magnitudes dos coeficientes de correlação foram classificadas conforme Carvalho et al. (2004): $\mathrm{r}=0$ (nula), $0<|\mathrm{r}| \leq 0,30$ (fraca), 0,30<|r $\mid \leq 0,60$ (média), 0,60 $<|\mathrm{r}| \leq 0,90$ (forte), $0,90<|\mathrm{r}| \leq 1$ (fortíssima) e $|\mathrm{r}|=1$ (perfeita).

As análises estatísticas foram realizadas com a utilização do programa GENES (Cruz, 2006).

\section{RESULTADOS E DISCUSSÃO}

Os caracteres apresentaram normalidade de distribuição de erros, exceto a aspereza de tubérculo (ASP), para ambas as gerações, sendo, este último, desconsiderado da análise de variância.
A análise de variância revelou diferenças significativas $(\mathrm{p}<0,05)$ entre as famílias avaliadas para todos os caracteres, com exceção do tamanho de tubérculo (TAM), para a geração de plântula $(\mathrm{p}=0,31)$ e primeira geração de campo $(\mathrm{p}=0,40)$; uniformidade de tamanho de tubérculo (UTA), para a geração de plântula $(\mathrm{p}=0,17)$ e formato $(\mathrm{FOR})(\mathrm{p}=0,10)$ e apontamento de tubérculo (APO) $(\mathrm{p}=$ $0,18)$, para a primeira geração de campo.

$\mathrm{Na}$ análise conjunta das duas gerações, a interação progênies $x$ gerações foi significativa para os caracteres FOR $(p=0,05), \operatorname{APO}(p=0,005), \operatorname{UTA}(p=0,02)$, número de tubérculos (NTU) $(\mathrm{p}=0,004)$, massa de tubérculos por planta $(\mathrm{MAS})(\mathrm{p}=0,003)$, e massa média de tubérculos por planta (MAM) $(\mathrm{p}=0,0006)$.

Considerando-se os caracteres para os quais a interação progênies x gerações não foi significativa, verificou-se que os coeficientes de variação fenotípicos (CV) variaram de $5,74 \%$, para $\mathrm{ACH}$, a $14,97 \%$, para proeminência de sobrancelha nos tubérculos (SOB), enquanto, para os caracteres que apresentaram interação significativa, observou-se que, na geração de plântula, os CV variaram de $5,60 \%$, para FOR, a $11,80 \%$, para MAM. Para a primeira geração de campo, verificaram-se $\mathrm{CV}$, variando de 3,87\% para APO, a 14,66\%, para MAS. Em geral, os valores de CV foram maiores para os caracteres APA, MAS, NTU e MAM, que são conhecidamente caracteres quantitativos e, portanto, sujeitos a maior influência ambiental. Mesmo assim, pode-se concluir que a precisão experimental, obtida nos experimentos, foi adequada e está de acordo com resultados encontrados na literatura (Silva et al., 2006; Andreu, 2005; Silva et al., 2007; Silva et al., 2008; Melo et al., 2011; Fekadu et al., 2013).

Considerando-se os caracteres que foram significativos pela análise de variância, em ambas as gerações, e as correlações que também foram significativas nas duas gerações, verificaram-se associações moderadas e positivas para ASP x profundidade de olhos (OLH), curvatura (CUR) x uniformidade de formato (UFO), ACH x CUR, UFO x aparência geral (APA), MAS x MAM, e NUT x MAM; moderada a forte para APA x ASP; fortes para MAS x NTU; e de forte a fortíssimo para SOB x OLH (Tabela 1).

Correlações negativas e médias foram verificadas, apenas na geração de plântula, para APO x FOR, CUR x FOR, APO x ASP, APO x OLH; positivas e médias entre APO $x$ UFO, APA x OLH, APA x SOB, APA x NUM e APA x MAS e fortes e positivas para CUR x APO, APO x ACH, enquanto, apenas na primeira geração clonal, a correlação média e positiva foi verificada entre UFO x UTA (Tabela 1).

As associações de menor aspereza com menor profundidade de olhos e de menor profundidade dos olhos com menor proeminência da sobrancelha confirmam relatos anteriores (Silva et al., 2007; Silva et al., 2009). 
Os resultados de correlação entre MAS x NUT e MAS $\mathrm{x}$ MAM indicam que quanto maior o número e a massa média dos tubérculos, maior é a massa total de tubérculos. Estes resultados assemelham-se aos obtidos por outros autores (Silva et al., 2007; Silva et al., 2009; Khayatnezhad et al. 2011). Correlações muito baixas entre NUT e MAM foram encontradas por Gopal et al. (1994) e Pinto et al. (1994). No entanto, a indicação de que maior número de tubérculos está correlacionado com menor massa média concorda com resultados obtidos por diversos autores (Galarreta et al., 2006; Silva et al., 2007; Silva et al., 2009) e indica que as plantas que apresentam menor número de tubérculos apresentam tubérculos maiores, graças à partição do amido acumulado para um menor número de drenos. Esta é uma relação muito importante, dada a sua influência na quantidade de tubérculos comercializáveis produzidos. Da mesma forma, Fekadu et al. (2013) verificaram correlação negativa entre número de tubérculos e percentagem de tubérculos grandes.

As correlações de FOR com APO e CUR indicam que em tubérculos mais alongados há maior expressão dos caracteres apontamento e curvatura. Isso porque o formato mais arredondado desfavorece a curvatura e apontamento dos tubérculos e vice versa (Silva et al., 2007).

As correlações entre APO e ASP e entre APO e OLH são indesejáveis do ponto de vista do melhoramento, pois, com a seleção para tubérculos menos apontados seriam obtidos tubérculos mais ásperos e com olhos profundos. No entanto, as correlações verificadas entre APO e CUR, em que tubérculos menos apontados são menos curvados, e ACH e UFO, indicando que tubérculos menos achatados são mais uniformes em formato, são desejáveis. As correlações entre APO e OLH, ASP e CUR provavelmente são influenciadas pelo formato dos tubérculos, pois, apesar de apenas as correlações entre FOR x APO, FOR x CUR terem sido significativas, é comum em algumas populações que tubérculos mais arredondados apresentem maior ASP e OLH (Silva et al., 2008b; Silva et al., 2009). Além disso, principalmente na geração de plântula, foram verificadas inter-relações significativas entre os caracteres OLH, ASP e CUR.

A correlação de magnitude moderada entre UFO e UTA indica que a seleção para plantas com tubérculos mais uniformes em formato leva à obtenção de tubérculos mais uniformes em tamanho. Esta associação também foi verificada por Silva et al. (2007), nas gerações de plântula e primeira geração clonal, e por Silva et al. (2008), na geração de plântula.

As associações entre CUR, ACH e UFO indicam que curvatura de tubérculo menos acentuada é verificada em tubérculos menos achatados e mais uniformes em formato, situação que também favorece o melhoramento (Tabela 1). Este mesmo comportamento foi observado por Silva et al. (2007), porém significativo apenas na primeira geração clonal.

A manifestação das características nos tubérculos, de forma diferente nas gerações distintas, pode ser devida ao tamanho e ao número de tubérculos, que sempre é menor na geração de plântula. Sendo assim, as características fenotípicas poderiam ser mais facilmente observadas a partir da primeira geração de campo. Estes fatores têm sido relatados como causa da ineficiência da seleção ainda na geração de plântula (Anderson \& Howard, 1981; Brown et al., 1984; Gopal \& Minocha, 1997). No entanto, alguns estudos indicam que mesmo com estas diferenças,

Tabela 1. Correlações entre caracteres fenotípicos de tubérculos de batata, avaliados na geração de plântula, safra 2010/2011 (diagonal inferior) e primeira geração de campo, safra 2011/2012 (diagonal superior)

\begin{tabular}{lccccccccccccc}
\hline Caráter & ASP $^{1}$ & OLH & SOB & FOR & UFO & APO & CUR & ACH & APA & UTA & NTU & MAS & MAM \\
\hline ASP & & $0,32^{*}$ & 0,28 & 0,35 & $-0,05$ & $-0,27$ & $-0,19$ & $0,39^{*}$ & $0,42^{*}$ & $-0,37^{*}$ & 0,14 & 0,04 & $-0,08$ \\
OLH & $0,38^{*}$ & & $0,89^{*}$ & 0,07 & 0,05 & $-0,01$ & $-0,01$ & $-0,02$ & $-0,02$ & 0,03 & $-0,09$ & $-0,16$ & $-0,14$ \\
SOB & $0,38^{*}$ & $0,95^{*}$ & & $-0,03$ & 0,10 & $-0,07$ & 0,02 & $-0,01$ & $-0,04$ & 0,02 & $-0,14$ & $-0,22$ & $-0,12$ \\
FOR & 0,17 & 0,12 & 0,10 & & $-0,14$ & $-0,45$ & $-0,33$ & 0,06 & 0,25 & $-0,32$ & $-0,18$ & $-0,05$ & 0,15 \\
UFO & $-0,13$ & $-0,18$ & $-0,11$ & $-0,61^{*}$ & & 0,28 & $0,48^{*}$ & 0,19 & $0,33^{*}$ & $0,41^{*}$ & 0,27 & $0,34^{*}$ & 0,13 \\
APO & $-0,45^{*}$ & $-0,34^{*}$ & $-0,29$ & $-0,54^{*}$ & $0,58^{*}$ & & 0,69 & $-0,02$ & 0,16 & 0,23 & 0,05 & 0,16 & 0,08 \\
CUR & $-0,36^{*}$ & $-0,34^{*}$ & $-0,26$ & $-0,48^{*}$ & $0,57^{*}$ & $0,90^{*}$ & & $0,32^{*}$ & $0,40^{*}$ & 0,14 & 0,02 & 0,19 & 0,20 \\
ACH & $-0,26$ & $-0,16$ & $-0,10$ & $-0,24$ & $0,42^{*}$ & $0,61 *$ & $0,51^{*}$ & & $0,39^{*}$ & $-0,43^{*}$ & 0,18 & 0,04 & $-0,09$ \\
APA & $0,62^{*}$ & $0,32^{*}$ & $0,36^{*}$ & $-0,24$ & $0,40^{*}$ & 0,12 & 0,23 & 0,15 & & $-0,09$ & 0,22 & 0,30 & 0,16 \\
UTA & 0,13 & $-0,07$ & $-0,01$ & $-0,24$ & 0,46 & 0,13 & 0,05 & 0,13 & 0,34 & & $-0,08$ & 0,02 & 0,04 \\
NTU & $0,45^{*}$ & $-0,07$ & $-0,12$ & $-0,23$ & 0,29 & 0,18 & 0,13 & $0,40^{*}$ & $0,57^{*}$ & 0,40 & & $0,70^{*}$ & $-0,32^{*}$ \\
MAS & $0,43^{*}$ & $-0,25$ & $-0,25$ & 0,02 & 0,10 & $-0,03$ & $-0,01$ & 0,03 & $0,38^{*}$ & 0,39 & $0,66^{*}$ & & $0,38^{*}$ \\
MAM & 0,00 & $-0,27$ & $-0,20$ & $0,37^{*}$ & $-0,24$ & $-0,22$ & $-0,12$ & $-0,34^{*}$ & $-0,18$ & 0,02 & $-0,33^{*}$ & $0,44^{*}$ & \\
\hline
\end{tabular}

${ }^{1}$ ASP: aspereza; OLH: profundidade de olho; SOB: sobrancelha; FOR: formato; UFO: uniformidade de formato; APO: apontamento; CUR: curvatura de tubérculo; ACH: achatamento de tubérculo; APA: aparência; UTA: uniformidade de tamanho de tubérculo; NTU: número de tubérculos; MAS: massa de tubérculo ( $\mathrm{g}$ planta $\left.{ }^{-1}\right)$; MAM: massa média de tubérculo (g). *Significativamente diferente de zero a $5 \%$ de probabilidade pelo teste $t$, para caracteres que apresentaram diferenças significativas na análise de variância. 
a expressão de algumas características se mantém nestas gerações, tornando possível a seleção ainda na geração de plântula (Bisognin \& Douches, 2002; Hayes \& Thill, 2002; Xiong et al., 2002; Galarreta et al., 2006).

Neste estudo, as correlações entre as gerações, que são indicativas da herdabilidade, foram significativas para OLH, SOB, MAS, NUT, ACH e CUR. Estas magnitudes sugerem que a seleção de intensidade fraca a moderada poderia ser aplicada para estes caracteres na geração de plântula (Tabela 2). Outros estudos também analisaram correlações entre gerações. Brown \& Caligari (1986) verificaram coeficientes de correlação similares, entre a geração de plântula e primeira geração de campo, para rendimento de tubérculos, número e massa média de tubérculos. Os autores ressaltaram, no entanto, que estas correlações podem ter sido superestimadas pela influência do tamanho dos tubérculos que foram plantados na primeira geração clonal. Maris (1988) também relatou correlação significativa para número de tubérculos e massa média de tubérculos, entre a geração de plântula e a primeira geração clonal, e, Xiong et al. (2002), para peso específico. Gopal (1997), estudando as gerações de plântula e primeira geração clonal, ambas cultivadas a campo, encontrou correlações significativas para rendimento e número de tubérculos, aparência geral, coloração, formato, uniformidade de formato e massa média de tubérculos. Silva et al. (2008) verificaram que aparência, aspereza, formato, sobrancelha, apontamento, curvatura e achatamento de tubérculo mantiveram suas expressões, da geração de plântula para a primeira e a segunda gerações clonais. Rigão et al. (2009), na sequência das três primeiras gerações clonais de seleção, observaram correlação para os caracteres comprimento de tubérculo, medida do maior diâmetro, medida do menor diâmetro e matéria fresca. Estes autores observaram que o comprimento de tubérculo apresentou a maior associação entre os tubérculos plantados e colhidos, indicando que a seleção nas gerações iniciais seria eficiente. Da mesma forma, Galarreta et al. (2006) verificaram correlações significativas e de média magnitude para número de tubérculos, entre a geração de plântula cultivada em casa de vegetação e as duas primeiras gerações clonais de campo e correlações significativas e de baixa magnitude para massa média de tubérculos; enquanto, para rendimento de tubérculos foram verificadas correlações significativas, mas de baixa magnitude, apenas entre as duas primeiras gerações clonais.

A aparência de tubérculo é um caráter complexo e normalmente de herdabilidade menor do que a dos seus caracteres componentes (Maris, 1988). Este caráter mostrou-se significativamente associado, na geração de plântula, com aspereza de tubérculo, profundidade de olhos, proeminência de sobrancelha, uniformidade de formato, além de correlacionado também com o número e a massa de tubérculos. Na primeira geração clonal, aparência de tubérculos correlacionou-se significativamente apenas com aspereza de tubérculo e uniformidade de formato (Tabela 1). O melhor entendimento destas relações pode ser obtido por meio da análise de trilha, estimandose os efeitos diretos e indiretos dos diferentes caracteres em relação à aparência de tubérculo (Tabela 3 ). Os coeficientes de determinação foram de 0,77 , para a geração de plântula, e 0,71 , para a primeira geração clonal, indicando que o caráter principal está bem representado pelos caracteres componentes. A análise de trilha, baseada na aparência de tubérculo como uma variável dependente, revelou que todos os caracteres, exceto os caracteres OLH e SOB, na primeira geração clonal, e FOR, APO, ACH e MAS, na geração de plântula, mostraram efeitos diretos positivos.

Pode-se verificar que, depois de retirados os efeitos indiretos, os caracteres que mais influenciaram na aparência geral dos tubérculos, em ambas as gerações, foram aspereza $(0,45$ e 0,56$)$ e curvatura de tubérculo $(0,49$ e 0,41 ), sendo a melhor aparência relacionada com tubérculos menos ásperos e curvados. Número de tubérculos teve influência destacada $(0,51)$, mas somente na geração de plântula. Os demais componentes apresentaram baixa influência direta na aparência. Estes resultados indicam que, nas primeiras duas gerações de seleção, os caracteres curvatura e aspereza de tubérculo influenciam na aparência geral de tubérculo, confirmando relatos de Silva et al. (2007) e Silva et al. (2009).

Tabela 2. Correlações de Spearman entre a geração de plântula (safra 2010/2011) e primeira geração de campo (safra 2011/2012), para caracteres fenotípicos de tubérculo de batata

\begin{tabular}{llllllcc}
\hline Caráter & ASP $^{1}$ & OLH & SOB & FOR & UFO & APO & CUR \\
\hline Correlação & $-0,01$ & $0,69^{* *}$ & $0,58^{* *}$ & 0,13 & 0,15 & 0,07 & $0,36^{*}$ \\
\hline Caráter & ACH & APA & UTA & NTU & MAS & MAM & - \\
\hline Correlação & $0,39^{*}$ & 0,29 & $-0,05$ & $0,50^{* *}$ & $0,51^{* *}$ & 0,28 & - \\
\hline
\end{tabular}

${ }^{1}$ ASP: aspereza; OLH: profundidade de olho; SOB: sobrancelha; FOR: formato; UFO: uniformidade de formato; APO: apontado; CUR: curvatura de tubérculo; ACH: achatamento de tubérculo; APA: aparência; UTA: uniformidade de tamanho de tubérculo; NTU: número de tubérculos; MAS: massa de tubérculo (g planta $\left.{ }^{-1}\right)$; MAM: massa média de tubérculo $(\mathrm{g})$. ${ }^{*}$ Significativamente diferente de zero a $5 \%$ de probabilidade.

Rev. Ceres, Viçosa, v. 61, n.3, p. 370-376, mai/jun, 2014 
Tabela 3. Análise de trilha para aparência de tubérculos de batata na geração de plântula (safra 2010/2011) e primeira geração clonal (safra 2011/2012)

\begin{tabular}{|c|c|c|c|c|c|c|c|c|c|c|c|c|}
\hline \multirow{3}{*}{ Caráter } & \multicolumn{11}{|c|}{ Efeito Indireto $^{1}$} & \multirow{3}{*}{$\begin{array}{c}\text { Efeito } \\
\text { Direto }^{4}\end{array}$} \\
\hline & \multicolumn{11}{|c|}{ Geração de plântula } & \\
\hline & $\mathbf{A S P}^{3}$ & OLH & SOB & FOR & UFO & APO & CUR & $\mathrm{ACH}$ & NTU & MAS & MAM & \\
\hline $\mathrm{ASP}^{2}$ & & 0,02 & 0,11 & $-0,01$ & $-0,03$ & 0,08 & $-0,17$ & 0,01 & 0,22 & $-0,07$ & 0,00 & 0,45 \\
\hline OLH & 0,17 & & 0,26 & $-0,01$ & $-0,04$ & 0,07 & $-0,17$ & 0,01 & $-0,03$ & 0,04 & $-0,06$ & 0,07 \\
\hline SOB & 0,16 & 0,06 & & $-0,01$ & $-0,02$ & 0,05 & $-0,13$ & 0,00 & $-0,06$ & 0,04 & $-0,04$ & 0,28 \\
\hline FOR & 0,07 & 0,01 & 0,03 & & $-0,14$ & 0,10 & $-0,23$ & 0,01 & $-0,11$ & $-0,01$ & 0,08 & $-0,04$ \\
\hline UFO & $-0,05$ & $-0,01$ & $-0,03$ & 0,03 & & $-0,11$ & 0,28 & $-0,02$ & 0,15 & $-0,02$ & $-0,05$ & 0,24 \\
\hline APO & $-0,20$ & $-0,02$ & $-0,08$ & 0,02 & 0,14 & & 0,44 & $-0,03$ & 0,09 & 0,01 & $-0,05$ & $-0,19$ \\
\hline CUR & $-0,16$ & $-0,02$ & $-0,07$ & 0,02 & 0,14 & $-0,17$ & & $-0,03$ & 0,06 & 0,01 & $-0,02$ & 0,49 \\
\hline $\mathrm{ACH}$ & $-0,11$ & $-0,01$ & $-0,03$ & 0,01 & 0,10 & $-0,12$ & 0,24 & & 0,20 & $-0,01$ & $-0,07$ & $-0,06$ \\
\hline NTU & 0,20 & $-0,01$ & $-0,03$ & 0,01 & 0,07 & $-0,03$ & 0,06 & $-0,02$ & & $-0,12$ & $-0,07$ & 0,51 \\
\hline MAS & 0,19 & $-0,01$ & $-0,07$ & 0,00 & 0,02 & 0,00 & 0,00 & 0,00 & 0,33 & & 0,09 & $-0,18$ \\
\hline MAM & 0,00 & $-0,01$ & $-0,06$ & $-0,02$ & $-0,06$ & 0,04 & $-0,06$ & 0,02 & $-0,16$ & $-0,07$ & & 0,21 \\
\hline \multicolumn{13}{|c|}{ Primeira geração clonal } \\
\hline & ASP & OLH & SOB & UFO & CUR & $\mathrm{ACH}$ & UTA & NTU & MAS & MAM & - & \\
\hline $\mathrm{ASP}^{2}$ & & $-0,03$ & $-0,03$ & $-0,01$ & $-0,07$ & 0,01 & $-0,01$ & 0,01 & 0,00 & 0,00 & - & 0,56 \\
\hline OLH & 0,18 & & $-0,09$ & 0,01 & $-0,01$ & 0,00 & 0,00 & 0,00 & 0,00 & $-0,01$ & - & $-0,09$ \\
\hline SOB & 0,16 & $-0,08$ & & $-0,01$ & 0,01 & 0,00 & 0,00 & $-0,01$ & $-0,01$ & $-0,01$ & - & $-0,09$ \\
\hline UFO & $-0,03$ & $-0,01$ & 0,01 & & 0,20 & 0,00 & 0,01 & 0,02 & 0,00 & 0,01 & - & 0,10 \\
\hline CUR & $-0,10$ & 0,00 & 0,00 & 0,05 & & 0,00 & 0,00 & 0,00 & 0,00 & 0,02 & - & 0,41 \\
\hline $\mathrm{ACH}$ & 0,21 & 0,00 & 0,00 & 0,04 & 0,05 & & $-0,01$ & $-0,01$ & 0,00 & 0,00 & - & 0,02 \\
\hline UTA & $-0,20$ & 0,00 & 0,00 & 0,04 & 0,05 & & $-0,01$ & $-0,01$ & 0,00 & 0,00 & - & 0,04 \\
\hline NTU & 0,08 & 0,00 & 0,01 & 0,03 & 0,01 & 0,00 & & 0,00 & 0,01 & $-0,03$ & - & 0,09 \\
\hline MAS & 0,02 & 0,01 & 0,02 & 0,03 & 0,07 & 0,00 & 0,00 & & 0,06 & 0,04 & - & 0,02 \\
\hline MAM & $-0,04$ & 0,01 & 0,01 & 0,01 & 0,08 & 0,00 & 0,00 & $-0,03$ & & 0,00 & - & 0,10 \\
\hline
\end{tabular}

${ }^{1}$ EI- Efeito indireto, dos caracteres $\left({ }^{2}\right)$ via os caracteres $\left({ }^{3}\right)$ sobre aparência; ${ }^{4}$ ED- Efeito direto, dos caracteres $\left({ }^{2}\right)$ sobre a aparência. ASP: aspereza; OLH: profundidade de olho; SOB: sobrancelha; FOR: formato; UFO: uniformidade de formato; APO: apontado; CUR: curvatura de tubérculo; ACH: achatamento de tubérculo; TAM: tamanho de tubérculo; UTA: uniformidade de tamanho de tubérculo; NTU: número de tubérculos; MAS: massa de tubérculo $\left(\mathrm{g}\right.$ planta $\left.{ }^{-1}\right)$; MAM: massa média de tubérculo (g).

\section{CONCLUSÕES}

Os caracteres aparência e aspereza de tubérculo, curvatura e apontamento, massa e número de tubérculos, e, proeminência da sobrancelha e profundidade de olhos são fortemente e favoravelmente correlacionados nas duas primeiras gerações de seleção.

O grau de correlação entre as duas primeiras gerações para profundidade de olho, proeminência de sobrancelha, massa de tubérculo, número de tubérculo, curvatura de tubérculo e apontamento de tubérculo indica que seleção para estes caracteres pode ser aplicada na geração de plântula.

Aspereza e curvatura de tubérculo são os caracteres que mais influenciam na aparência geral. Portanto, sua seleção pode ser utilizada no melhoramento para aparência geral de tubérculo.

\section{REFERÊNCIAS}

Agrianual (2012) Anuário da Agricultura Brasileira. São Paulo, FNP. p.189-296.
Anderson JAD \& Howard HW (1981) Effectiveness of selection in the early stages of potato breeding programmes. Potato Research, 24:289-299.

Andreu AA (2005) Associação entre características agronômicas da batata nos plantios de primavera e outono no Rio Grande do Sul. Ciência e Agrotecnologia, 9:925-929.

Barbosa MHP (1996) Capacidade combinatória e comparação entre critérios de seleção de clones de batata. Tese de Doutorado. Universidade Federal de Lavras, Lavras. 138p.

Bisognin DA \& Douches DS (2002) Early generation selection for potato tuber quality in progenies of late blight resistant parents. Euphytica, 127:1-9.

Brown J, Caligari PDS, Mackay GR \& Swan GEL (1984) The efficiency of seedling selection by visual preference in a potato breeding programme. Journal of Agricultural Science, 103:339-346.

Brown J \& Caligari PDS (1986) The efficiency of seedling selection for yield and yield components in a potato breeding programme. Pflanzenzuchtg, 96:53-62.

Camargo Filho WP (2001) Produto Interno Bruto (PIB) da cadeia produtiva da batata. Batata Show, 1:22.

Campos H de (1983) Estatística experimental não-paramétrica. $4^{\mathrm{a}}$ ed. Piracicaba, FEALQ. 349p.

Carvalho FIF de, Lorencetti C \& Benin G (2004) Estimativas e implicações da correlação no melhoramento vegetal. Pelotas, Editora UFPel. 142p. 
Cruz CD (2006) Programa Genes: biometria. Viçosa, UFV. 382p.

Cruz CD \& Regazzi AJ (2001) Métodos biométricos aplicados ao melhoramento genético. Viçosa, Editora UFV. 390p.

Fekadu A, Petros Y \& Zelleke H (2013) Genetic variability and association between agronomic characters in some potato (Solanum tuberosum L.) genotypes in SNNPRS, Ethiopia. International Journal of Biodiversity and Conservation, 5:523528.

Galarreta JIR, Ezpelata B, Pascualena J \& Ritter E (2006) Combining ability in early generations of potato breeding. Plant Breed, 125:183-186.

Gopal J (1997) Progeny Selection for agronomic characters in early generations of a potato breeding programme. Theoretical Applied Genetics, 95:307-311.

Gopal J, Gaur PC \& Rana MS (1994) Heritability, and intra- and inter-generation associations between tuber yield and its components in potato (Solanum tuberosum L.). Plant Breeding, 112:80-83.

Gopal J \& Minocha JL (1997) Effectiveness of selection at microtuber crop level in potato. Plant Breeding, 116:293-295.

Hayes RJ \& Thill CA (2002) Selection for cold chipping genotypes from three early generations in a potato breeding program. Euphytica, 128:353-362.

Khayatnezhad MR, Shahriari BR \& Gholamin RG (2011) Correlation and path analysis between yield and yield components in potato (Solanum tubersum L.). Journal of Scientific Research, 7:17-21.

Maris B (1988) Correlations within and between characters between and within generations as a measure for the early generation selection in potato breeding. Euphytica, 37:205-209.

Melo DS, Pinto CABP, Peixouto LS, Neder DG \& Assis GCE (2011) Early selection of full-sib potato families. Ciência e Agrotecnologia, 35:1101-1109.
Pinto CAB, Vanderlei IRV \& Rossi MS (1994) Eficiência da seleção nas primeiras gerações clonais em batata (Solanum tuberosum L.). Pesquisa Agropecuária Brasileira, 29:771-778.

Rigão MH, Storck L, Bisognin DA \& Lopes SJ (2009) Correlação canônica entre caracteres de tubérculos para seleção precoce de clones de batata. Ciência Rural, 39:2347-2353.

Siegel S (1975) Estatística não-paramétrica para as ciências do comportamento. São Paulo, McGraw-Hill do Brasil. 100p.

Silva GO da, Pereira A da S, Souza VQ de, Carvalho FIF de \& Neto RF (2006) Early generation selection for tuber appearance affects potato yield components. Crop Breeding and Applied Biotechnology, 6:73-78.

Silva GO, Pereira AS, Souza VQ, Carvalho FIF \& Neto RF (2007) Correlações entre caracteres de aparência e rendimento e análise de trilha para aparência de batata. Bragantia, 66:381-388.

Silva GO da, Pereira A da S, Souza VQ de, Carvalho FIF de \& Fritsche Neto R (2008) Seleção para caracteres fenotípicos de tubérculos nas primeiras gerações em batata. Revista Ceres, 55:168-172.

Silva GO, Pereira AS, Souza VQ, Carvalho FIF \& Fritsche Neto R (2008b) Seleção para caracteres componentes de aparência e rendimento de tubérculo em plântulas de batata. Horticultura Brasileira, 26:323-327.

Silva GO, Pereira AS, Souza VQ, Carvalho FIF \& Neto RF (2009) Correlações entre caracteres fenotípicos e análise de trilha para aparência e rendimento de batata. Revista Ceres, 56:63-68.

Silva GO \& Pereira AS (2011) Seleção em gerações iniciais para caracteres agronômicos em batata. Horticultura Brasileira, 29:449-455.

Steel RGD \& Torrie JH (1980) Principles and procedures of statistics. $2^{a}$ ed. New York, McGraw-Hill Book. 633p.

Xiong X, TAI GCC \& Seabrook JEA (2002) Effectiveness of selection for quality traits during the early stage in the potato breeding population. Plant Breeding, 121:441-444. 